\title{
Pendampingan Komunitas UMKM Batu Bata melalui Penggunaan Aplikasi Perhitungan Stock berbasis E-commerce di Desa Pasir Putih Ujung Kecamatan Talang Kelapa Kabupaten Banyuasin
}

\author{
Hendra Hadiwijaya ${ }^{1}$, Febrianty ${ }^{1}$, Darmawi $^{2}$ \\ ${ }^{1}$ Politeknik Palcomtech; ${ }^{2}$ Universitas Sriwijaya Palembang \\ hendra_hadi@palcomtech.ac.id; febrianty@palcomtech.ac.id
}

\begin{abstract}
Identification of problems faced by partners in the Daslan Brick Business Partners in Pasir Putib Village, Talang Kelapa District, Banyuasin Regency, namely: lack of knowledge about product marketing strategies because they are still waiting for buyers and stocking bricks. Based on priority issues that must be addressed, the solution offered to partners is to increase knowledge about the product marketing strategy through e-commerce that will be produced and training in the application of calculating brick stock that will make it easier to know the amount of brick stock and record sales/ordering transactions. The target of this community service is to empower the Daslan Brick Business to become an independent business. After empowerment through appropriate technology produced and 8 (eight) months training and mentoring activities for Daslan Brick. Business partners, the detailed target is to increase knowledge about product marketing strategies. The work procedures in this business partnership program are as follows: appropriate technology development phase namely e-commerce web and brick stock calculation application, training phase, namely: training on e-commerce usage and application of brick stock calculation, and program evaluation stage. These community service results can increase partner business competitiveness by a minimum of 60\%; the application of science and technology by 75\%; and there was an increase in knowledge and skills by $70 \%$.
\end{abstract}

Keyword: Brick Business, Business Partnership Program, e-Commerce, Application of Brick Stock Calculation.

\section{Pendahuluan}

Kendala yang dihadapi usaha mikro kecil dan menengah (UMKM) untuk berkembang salah satunya adalah bidang pemasaran. ${ }^{1}$ Orientasi pasar UMKM menjadi rendah diakibatkan tidak atau kurang memadainya infrastruktur pemasaran UMKM tersebut. Oleh karena itu, penting tersedianya pasar yang jelas dan pasti bagi produk dan jasa UMKM agar UMKM dapat bersaing dalam pasar yang semakin kompetitif dan mekanisme pasar yang semakin terbuka. Salah satu solusi

\footnotetext{
1 Jaidan Jauhari, "Upaya Pengembangan Usaha Kecil dan Menengah (UKM) Dengan Memanfaatkan ECommerce," Jurnal Sistem Informasi 2, no. 1 (2014); Mike Simpson dkk., "Marketing in Small and Medium Sized Enterprises," International Journal of Entrepreneurial Behavior \& Research 12, no. 6 (2006): 361-387; Moch Khafidz Fuad Raya, "Marketing Jasa Di Institusi Pendidikan (Analisis Pemasaran dalam Pendidikan)," FALASIFA: Jurnal Studi Keislaman 7, no. 1 (2016): 21-52.
}

Volume 3, Number 2, November 2019| 262 Pendampingan Komunitas UMKM Batu Bata melalui Penggunaan Aplikasi Perhitungan Stock berbasis Ecommerce di Desa Pasir Putih Ujung Kecamatan Talang Kelapa Kabupaten Banyuasin 


\section{ENGAGEMENT}

Guinal QPengabdian YTepadtar Masyarafat

penguasaan pasar adalah dengan pemanfaatan teknologi digital marketing. ${ }^{2}$ Konten telah menjadi salah satu elemen terpenting dalam digital marketing. Pemasaran konten telah memberikan informasi penting kepada perusahaan dan konsumen, sharing dan percakapan berkualitas dapat dilakukan dimana dan kapan saja ${ }^{3}$

Salah satu kecamatan sentra produksi batu bata di Banyuasin, yakni Kecamatan Talang Kelapa yang cukup terkenal di wilayah Sumsel yang memiliki banyak UMKM Batu Bata sehingga disebut sebagai sentra produksi. Desa Pasir Putih berbatasan langsung dengan Kota Palembang. Berdasarkan data Pemerintahan Desa, tercatat ada \pm 400 bangsal batu bata di wilayah Pasir Putih. Batu bata yang diproduksi memiliki keunikan tersendiri dan berbeda dengan yang dihasilkan daerah lainnya. Kualitas bahan baku tanah liatnya lebih bagus dan dikenal sebagai tanah liat yang tahan api serta hasil batu bata lebih keras. Itulah sebabnya permintaan batu bata disini meningkat termasuk dari luar Palembang.

Mitra dalam kegiatan Program Kemitraan Usaha (PKM) ini adalah Usaha Batu Bata Daslan. Usaha Batu Bata Daslan merupakan salah satu bangsal batu bata yang berada di Jl. Camat Km.16 Desa Pasir Putih Ujung Kecamatan Talang Kelapa Kabupaten Banyuasin dan menjadi mitra pengabdian masyarakat. Usaha Batu Bata Daslan yang dimiliki oleh Bapak Daslan ini berdiri pada tahun 2005, memiliki 13 pekerja tetap. Hasil produksi dipasarkan disekitar wilayah dan juga sampai ke Kota Palembang, Kota Prabumulih, dan Kabupaten Muba. Kemampuan produksi batu bata bangsal Daslan sebanyak 2.000 buah/hari.
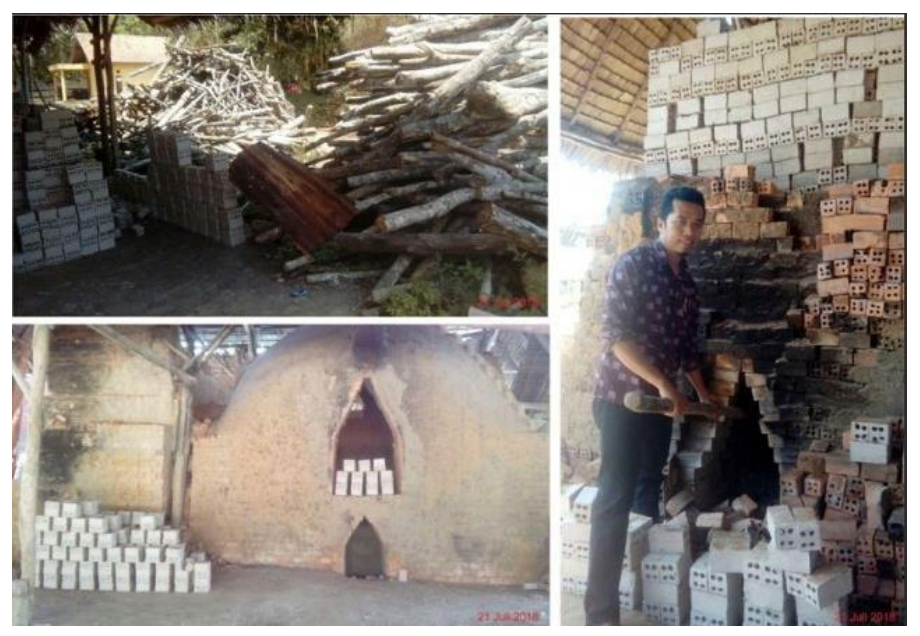

\section{Gambar1. Proses Pemanggangan Batu Bata di Bangsal Daslan}

\footnotetext{
2 Dave Chaffey dan Fiona Ellis-Chadwick, Digital Marketing (Pearson UK, 2019).

3 Febrianty dan Hendra Hadiwijaya, Optimasi omset UKM melalui Digital Marketing (Pekalongan: PT Nasya Expanding Management, 2019).

4 Wawancara dengan Bapak Daslan, 21 Juli 2018
}

Volume 3, Number 2, November 2019| 263 


\section{ENGAGEMENT}

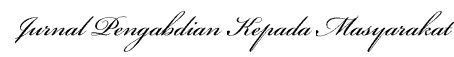

Walaupun usaha mitra telah berdiri sejak lama akan tetapi manajemen usaha masih bersifat kekeluargaan. Kurangnya pengetahuan manajemen usaha dan strategi pemasaran produk batu bata menyebabkan usaha mitra sulit berkembang. Manajemen sebagai sebuah proses perencanaan, pengorganisasian, pengkoordinasian, dan pengontrol sumber daya untuk mencapai sasaran secara efektif dan efisien ${ }^{5}$. Jadi, agar usaha dapat berjalan dengan maksimal sesuai dengan rencana yang telah ditentukan maka perlu diterapkan manajemen keuangan, manajemen sumber daya manusai (SDM), manajemen operasional, manajemen pemasaran. Apalagi jika dikaitkan dengan pemasaran usaha batu bata Daslan yang masih konvensional, seharusnya telah memanfaatkan teknologi untuk menangkap permintaan batu batu yang semakin meningkat. Seperti diketahui, manajemen pemasaran adalah kegiatan menganalisis, merencanakan, melaksanakan, dan mengendalikan program-program yang disusun dalam pembentukan, pembangunan, dan pemeliharaan keuntungan dari pertukaran/transaksi melalui sasaran pasar dengan harapan untuk mencapai tujuan perusahaan dalam jangka panjang ${ }^{6}$.

Sosial media pemasaran selain membantu pemasaran produk dan jasa, mengurangi mengurangi biaya promosi, melengkapi merek, dan mengadakan komunikasi timbal balik dengan pelanggan dan pemasok juga memiliki peran dalam membantu mengidentifikasi pelanggan, membagikan informasi untuk dapat mengetahui obyek yang disukai pelanggan, kehadiran pelanggan, hubungan antar pelanggan berdasarkan lokasi dan pola interaksi, reputasi perusahaan di mata pelanggan dan membentuk kelompok antar pelanggan ${ }^{7}$.

Pendampingan ini memfokuskan pada penerapan e-commerce dan aplikasi perhitungan stock batu bata pada komunitas UMKM Batu Bata. E-commerce adalah pemanfaatan internet dalam berbagai kegiatan usaha/bisnis yang meliputi: pemasaran, promosi, Public Relation (PR), transaksi, pembayaran, dan penjadwalan pengiriman barang, serta masih sangat terbuka kemungkinan inovasi-inovasi kegiatan bisnis online seiring dengan perkembangan teknologi e-commerce itu sendiri ${ }^{8}$. E-commerce telah mengubah cara banyak orang untuk membeli dan menjual secara online dan penggunaan aplikasi yang berbasis android menyebabkan hal yang semula rumit menjadi praktis

5 W Ricky Griffin, "Business, alih bahasa: Rd Soemarnagara," Jakarta: Erlangga, 2007.

6 Sofjan Assauri dan Manajemen Pemasaran, "Dasar, Konsep, dan Strategi," Edisi Pertama, Cetakan Kesembilan, Jakarta: Rajawali Pers, 2009.

7 Febrianty et al., "The Perception on Technology Acceptance to the Behaviors on the Use of Social Media for Marketing and Its Implications on the Turnover of Creative Industry MSMEs in Villages," Journal of Physics: Conference Series 1175, no. 1 (2019).

8 Yuswan Tio Arisandi, "Efektivitas Penerapan E-Commerce Dalam Perkembangan Usaha Kecil Menengah di Sentra Industri Sandal Dan Sepatu Wedoro Kabupaten Sidoarjo” (Universitas Airlangga, 2018). 


\section{ENGAGEMENT}

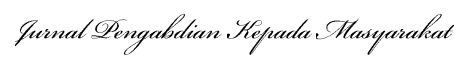

dilakukan'.

Penelitian Febrianty dan Fatmariani yang membangun e-commerce dengan nama $e-W a U K M$, sebagai sarana mengembangkan usaha waralaba versi grup UKM. Sistem $e-W a U K M$ yang dibangun dengan alamat link: https://e-waukm.com. memberikan solusi perluasan pasar bagi UKM dan peningkatan grade pelaku UMKM menjadi lebih berkelas ${ }^{10}$. Oleh karena itu, bagi Usaha Mikro Kecil dan Menengah (UMKM), memanfaatkan strategi pemasaran berbasis teknologi menjadi penting dan merupakan tuntutan untuk meningkatkan daya saing.

Berangkat dari latar belakang di atas, maka pendampingan ini dilakukan agar komunitas UMKM Batu Bata mendapatkan perbaikan manajemen usaha melalui: pelatihan pembuatan dan penyajian laporan keuangan dan pelatihan strategi pemasaran, serta mengetahui mengenai strategi pemasaran produk melalui e-commerce yang akan dihasilkan dengan menggunakan e-commerce. Disamping itu, komunitas juga memiliki kemampuan untuk memggunakan aplikasi perhitungan stock batu bata yang akan memudahkan dan mengetahui jumlah stock batu bata dan mencatat transaksi penjualan/pemesanan.

\section{Metode Pelaksanaan}

Metode yang digunakan dalam pendampingan ini melalui community development dengan beberapa rahapan sebagai berikut:

Pertama, tahap analisis situasi dan kondisi mitra. pada tahap ini tim pengabdi melalukan survei, pengumpulan data dan identifikasi masalah mitra, serta melakukan Focus Group Discussion (FGD) dengan mitra untuk jadwal pelaksanaan kegiatan pengabdian masyarakat.

Kedua, tahap persiapan dan pembuatan aplikasi e-commerce perhitungan stock batu bata. Pada tahap ini dilakukan dengan menyiapkan semua peralatan yang dibutuhkan untuk melaksanakan kegiatan dan pembuatan e-commerce dan aplikasi perhitungan stock batu bata. Selain itu, kegiatan penunjang, mulai dari studi literatur, koordinasi dengan mitra terkait, instansi, Kepala Desa/Lurah serta tokoh masyarakat yang membantu kegiatan program pengabdian masyarakat.

Ketiga, tahap pelatihan. Pada tahap ini tim pengabdi akan memulai kegiatan pelatihan sesuai dengan jadwal yang sudah ditentukan dan disepakati bersama dengan mitra. Tahap pelatihan menggunakan metode pelaksanaan untuk mengatasi masalah pemasaran yang dilakukan melalui

${ }_{9}^{9}$ Mochamad Mas'ud, "Pemanfaatan Teknologi Sistem Informasi untuk Meningkatkan Penjualan Hasil Produk UMKM Logam di Kota Pasuruan," Engagement : Jurnal Pengabdian Kepada Masyarakat 1, no. 2 SE-Articles (30 November 2017), https:/ /doi.org/10.29062/engagement.v1i2.14.

${ }^{10}$ Febrianty Febrianty dan Fatmariani Fatmariani, "e-WaUKM Sebagai Sarana Mengembangkan Usaha Waralaba Versi Grup UKM,” dalam Prosiding Seminar Nasional Hasil Litbangyasa Industri, vol. 1, 2018, 128-36.

Volume 3, Number 2, November 2019| 265

Pendampingan Komunitas UMKM Batu Bata melalui Penggunaan Aplikasi Perhitungan Stock berbasis Ecommerce di Desa Pasir Putih Ujung Kecamatan Talang Kelapa Kabupaten Banyuasin 


\section{ENGAGEMENT}

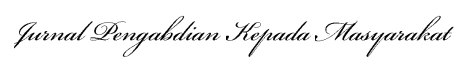

Pelatihan penggunaan e-commerce dan aplikasi perhitungan stock batu bata. Pelatihan ini akan dipandu dengan modul dan trainer dari tim pelaksana, dimana pemilik usaha akan dilatih penggunaan e-commerce sehingga diharapkan dapat memperluas pangsa pasar. Disamping itu juga penggunaan aplikasi perhitungan stock batu bata, dimana pelaku usaha dapat memanfaatkan aplikasi kalkulator tersebut dalam menjalankan usaha untuk menghitung stock batu bata dan mencatat transaksi penjualan/pemesanan.

Keempat, tahap evaluasi pendampingan. Pada tahap ini pelaksanaan kegiatan evaluasi oleh tim sendiri dan melihat apa saja kendala dan masalah yang muncul di lapangan. Kemudian dilakukan evaluasi apabila memang muncul kendala dan masalah untuk selanjutnya dicarikan solusi agar kegiatan tetap berlangsung dengan baik sesuai yang diharapkan. Evaluasi pelaksanaan pengabdian masyarakat dan keberlanjutan program setelah kegiatan pengabdian selesai melibatkan mitra, dan tentu saja pihak LPPM Politeknik Palcomtech Palembang. Evaluasi dilakukan dengan menggunakan kuesioner dan sejauh mana tingkat penerapan teknologi yang dilakukan oleh mitra (dalam bentuk Usability Testing/uji ketergunaan). Evaluasi tetap dilakukan walaupun program pengabdian selesai, dengan tetap memantau laporan penjualan usaha mitra dan penggunaan $e$ commerce dan aplikasi perhitungan stock batu bata.

\section{Hasil Dan Pembahasan}

Pelatihan UMKM menggunakan aplikasi pemasaran stock Batu Bara berbasis digital sebagai bentuk transformasi pemasaran dari tradisional menuju digital. ${ }^{11}$ Strategi pemasaran ini diadopsi untuk meningkatkan produktivitas penjualan yang lebih efisien dan informatif bagi UMKM yang saat ini sedang berkembang. ${ }^{12}$

Pelatihan penggunaan Aplikasi Pencatatan Batubata bagi UKM (APB-UKM) berbasis android dan e-commerce diilaksanakan selama dua hari oleh tim pengabdi. Selanjutnya adalah kegiatankegiatan pendampingan jika ada kendala yang dihadapi oleh mitra dalam penggunaan aplikasi tersebut. Sebagaimana yang dipaparkan oleh Taiminen dan Karjaluoto ${ }^{13}$ bahwa UKM yang menggunakan IT sebagai marketingnya (digital marketing) akan mempercepat informasi produk kepada konsumen dan masyarakat lebih tertarik serta termotivasi untuk memasarkan produknya.

\footnotetext{
${ }^{11}$ Raluca Dania Todor, "Blending Traditional and Digital Marketing," Bulletin of the Transilvania University of Brasov. Economic Sciences. Series V9, no. 1 (2016): 51.

12 Philip Alford dan Stephen John Page, "Marketing Technology for Adoption by Small Business," The Service Industries Journal 35, no. 11-12 (2015): 655-669.

${ }^{13}$ Heini Maarit Taiminen dan Heikki Karjaluoto, "The Usage of Digital Marketing Channels in SMEs," Journal of Small Business and Enterprise Development 22, no. 4 (2015): 633-651.
}

Volume 3, Number 2, November 2019| 266 Pendampingan Komunitas UMKM Batu Bata melalui Penggunaan Aplikasi Perhitungan Stock berbasis Ecommerce di Desa Pasir Putih Ujung Kecamatan Talang Kelapa Kabupaten Banyuasin 


\section{ENGAGEMENT}

Guinal QPengabdian YTepadtar Masyarafat

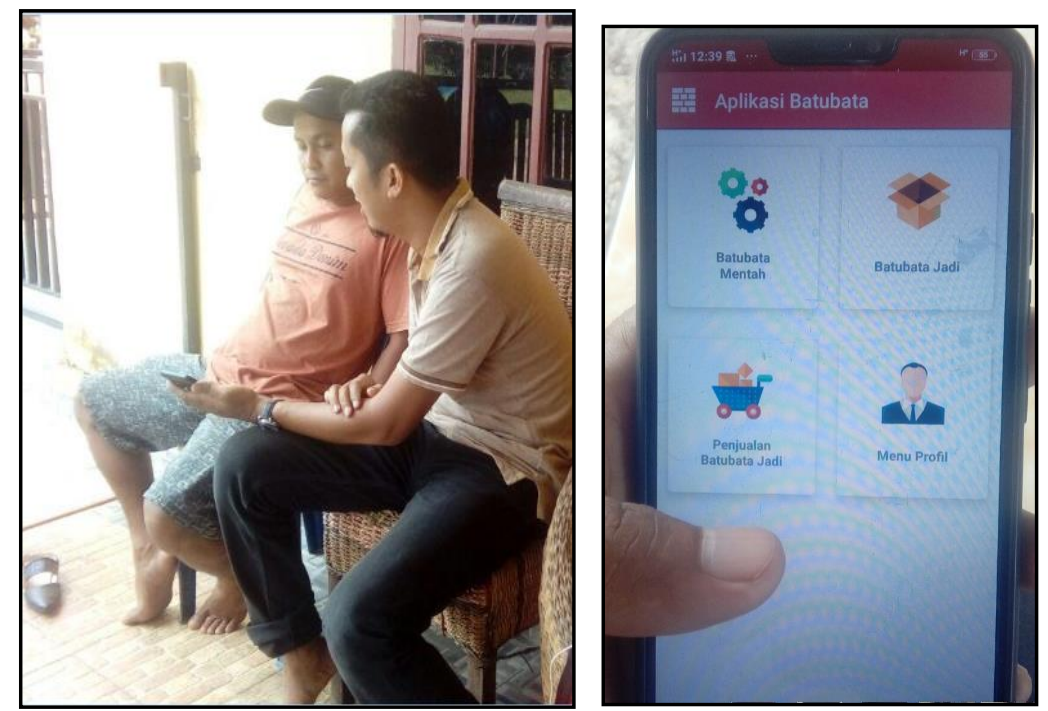

\section{Gambar 2. Kegiatan Pelatihan Penggunaan APB dan Tampilan APB UKM}

Tampilan menu awal Aplikasi Pencatatan Batubata bagi UKM (APB-UKM) yang terdiri dari: menu profil, batu bata mentah, batu bata jadi, penjualan batu bata jadi. Aplikasi ini dapat diunduh di play store android. Aplikasi Pencatatan Batubata bagi UKM (APB-UKM) ini dibuat lebih sederhana agar dapat mudah digunakan oleh mitra UMKM. Tim pengabdi memberikan penjelasan manfaat dari penggunaan dan mensimulasikan penggunaan Aplikasi Pencatatan Batubata bagi UKM (APB-UKM).

Adapun tampilan menu awal e-commerce Usaha Batu Bata Daslan yang menyediakan informasi berbagai jenis batu bata yang Depot Daslan sediakan. e-commerce juga menyediakan informasi layanan pemesanan dan pembayaran. E-commerce ini memiliki menu antara lain: home, profil, pelayanan, kontak, galeri, dan FAQ. Alamat e-commerce usaha Daslan adalah http://www.daslanonlineshop.store/. Berikut ini adalah tampilan menu home dan profil awal ecommerce Daslan:
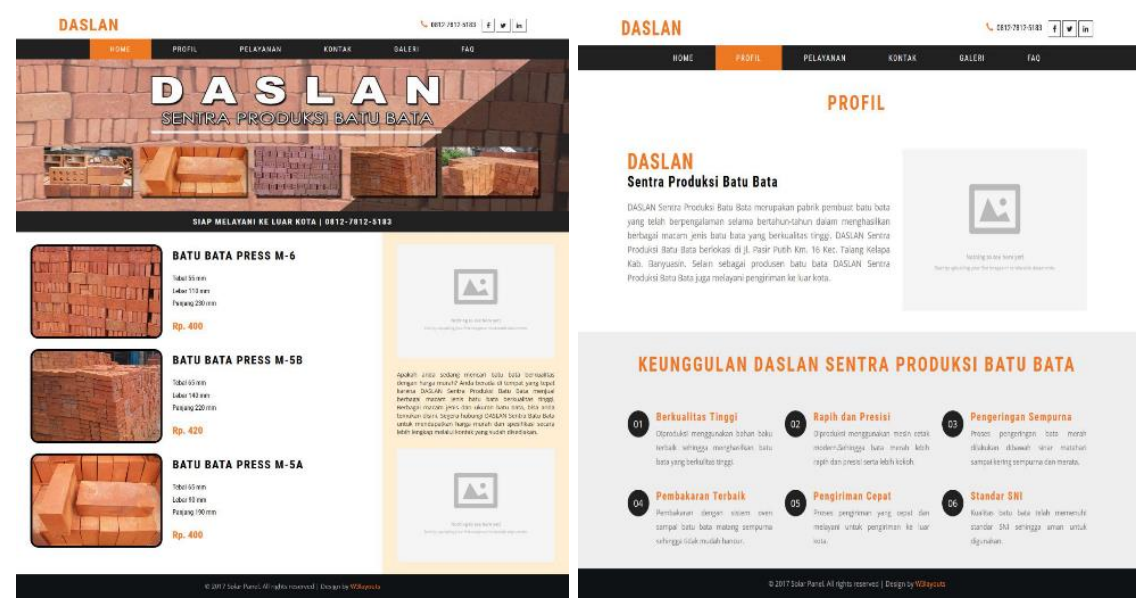

Gambar 3. Halaman Home dan Profil e-Commerce Usaha Batu Bata Daslan

Volume 3, Number 2, November 2019| 267

Pendampingan Komunitas UMKM Batu Bata melalui Penggunaan Aplikasi Perhitungan Stock berbasis Ecommerce di Desa Pasir Putih Ujung Kecamatan Talang Kelapa Kabupaten Banyuasin 


\section{ENGAGEMENT}

Kegiatan pelatihan dan pendampingan penggunaan e-commerce dilaksanakan selama dua hari. Kegiatan dilakukan berupa pengenalan fungsi e-commerce dan transaksi-transaksi dalam ecommerce. Pelatihan e-commerce ini menurut Abrahams dan Singh ${ }^{14}$ dimaksudkan untuk memberikan pemahaman dan pendidikan agar pelaku usaha UKM dapat memanfaatkan teknologi digital untuk memasarkan produknya.

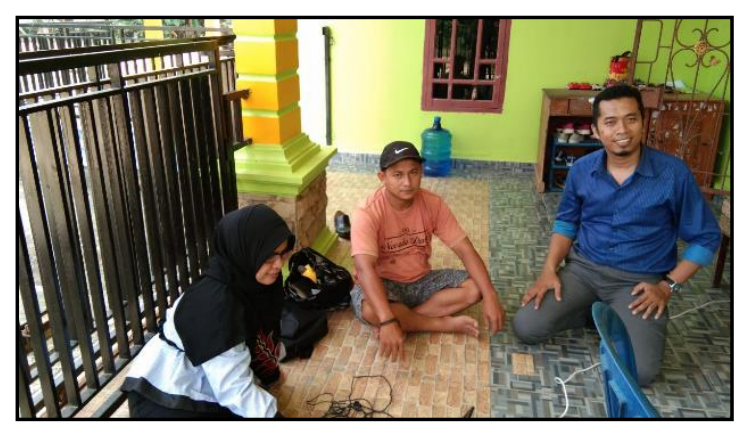

\section{Gambar 5. Pelatihan dan Pendampingan Penggunaan e-commerce}

Hasil dari kegiatan ini bagi Usaha Batu Bata Daslan adalah: (1) eningkatan pada penerapan IPTEK (penggunaan APB-UKM dan e-commerce), pengetahuan dan skill manajemen usaha; (2) pelaku usaha terbiasa menggunakan APB-UKM, yang berdampak pada mudahnya perhitungan stock batu bata dan mencatat transaksi penjualan/pemesanan; (3) pelaku usaha juga mudah mempersiapkan pesanan batu bata berikutnya sehingga semua pesanan dapat dipenuhi dengan baik; dan (4) pelaku usaha telah dapat mempromosikan secara luas produk batu bata dengan berbagai jenis ukuran dan yang memenuhi Standar Nasional Indonesia (SNI).

Evaluasi pelaksanaan pengabdian dan keberlanjutan program setelah kegiatan pengabdian selesai melibatkan mitra, dan tentu saja pihak LPPM Politeknik Palcomtech Palembang. Evaluasi dilakukan dengan menggunakan kuesioner dan sejauh mana tingkat penerapan teknologi yang dilakukan oleh mitra (dalam bentuk usability testing/uji ketergunaan). Evaluasi tetap dilakukan walaupun pengabdian masyarakat selesai, dengan tetap memantau penggunaan e-commerce dan aplikasi perhitungan stock batu bata.

\section{Simpulan}

${ }^{14}$ Alan S. Abrahams dan Tirna Singh, "An Active, Reflective Learning Cycle for E-Commerce Classes: Learning about E-Commerce by Doing and Teaching," Journal of Information Systems Education 21, no. 4 (2010): 383.

Volume 3, Number 2, November 2019| 268 Pendampingan Komunitas UMKM Batu Bata melalui Penggunaan Aplikasi Perhitungan Stock berbasis Ecommerce di Desa Pasir Putih Ujung Kecamatan Talang Kelapa Kabupaten Banyuasin 


\section{ENGAGEMENT}

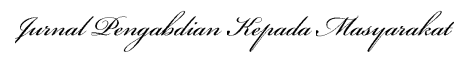

ISSN : 2579-8375 (Print) ISSN : 2579-8391 (Online)
This work is licensed under a Creative Commons Attribution-ShareAlike 4.0 International License. CC BY SA

Mitra usaha Daslan Batu Bata sebagai subyek dampingan telah menggunakan e-commerce dan aplikasi perhitungan stock batu bata dalam menjalankan usahanya. Sebelumnya pangsa pasar hanya terbatas pada wilayah Banyuasin, Kota Palembang, Kota Prabumulih, dan Kabupaten Muba, sejak menggnakan e-commerce pemasaran telah dapat menjangkau juga ke Kabupaten Ogan Ilir, Kabupaten Pali, dan Kabupaten Muara Enim. Disamping itu dengan penggunaan aplikasi perhitungan stock batu bata yang mirip dengan aplikasi kalkulator, mitra dapat menghitung stock batu bata dan mencatat transaksi penjualan/pemesanan sehingga dapat dengan mudah memantau persediaan batu bata dan kapan harus memproduksi batu bata dan dalam jumlah berapa banyak telah dapat diketahui dengan mudah. Dengan demikian, hasil pengabdian masyarakat ini dapat meningkatkan daya saing usaha mitra minimal sebesar 60\%; penerapan IPTEK sebesar 75\%; dan terjadi peningkatan pengetahuan dan skill sebesar 70\%.

\section{Ucapan Terimakasih}

Ucapan terimakasih yang sebesar-besarnya kepada pihak Direktorat Riset dan Pengabdian Masyarakat Direktorat Jenderal Penguatan Riset dan Pengembangan Kementerian Riset, Teknologi, dan Pendidikan Tinggi yang telah mendanai kegiatan PKM (pendanaan Tahun 2019). Begitu pula halnya dengan pihak manajemen khususnya LPPM Politeknik Palcomtech Palembang, yang telah memberikan kemudahan dan turut memfasilitasi kelacaran pelaksanaan pengabdian masyarakat ini.

\section{Daftar Pustaka}

Abrahams, Alan S., dan Tirna Singh. "An Active, Reflective Learning Cycle for E-Commerce Classes: Learning About E-Commerce by Doing and Teaching." Journal of Information Systems Education 21, no. 4 (2010): 383.

Alford, Philip, dan Stephen John Page. "Marketing Technology for Adoption by Small Business." The Service Industries Journal 35, no. 11-12 (2015): 655-669.

Arisandi, Yuswan Tio. "Efektivitas Penerapan E-Commerce Dalam Perkembangan Usaha Kecil Menengah di Sentra Industri Sandal Dan Sepatu Wedoro Kabupaten Sidoarjo.” Universitas Airlangga, 2018.

Assauri, Sofjan, dan Manajemen Pemasaran. "Dasar, Konsep, dan Strategi." Edisi Pertama, Cetakan Kesembilan, Jakarta: Rajawali Pers, 2009.

Chaffey, Dave, dan Fiona Ellis-Chadwick. Digital Marketing. Pearson UK, 2019.

Febrianty, Febrianty, dan Fatmariani Fatmariani. “e-WaUKM Sebagai Sarana Mengembangkan 


\section{ENGAGEMENT}

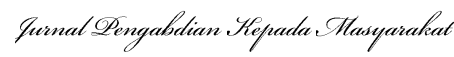

Usaha Waralaba Versi Grup UKM.” Dalam Prosiding Seminar Nasional Hasil Litbangyasa Industri, 1:128-36, 2018.

Febrianty, dan Hendra Hadiwijaya. Optimasi omset UKM melalui Digital Marketing. Pekalongan: PT Nasya Expanding Management, 2019.

Griffin, W Ricky. “Business, alih bahasa: Rd Soemarnagara.” Jakarta: Erlangga, 2007.

Febrianty, Divianto, Rahmat Hidayat, Fatmariani, and Tulus Rohana. "The Perception on Technology Acceptance to the Behaviors on the Use of Social Media for Marketing and Its Implications on the Turnover of Creative Industry MSMEs in Villages.” Journal of Physics: Conference Series 1175, no. 1 (2019)..

Jauhari, Jaidan. "Upaya Pengembangan Usaha Kecil Dan Menengah (UKM) Dengan Memanfaatkan E-Commerce." Jurnal Sistem Informasi 2, no. 1 (2014).

Mas'ud, Mochamad. "Pemanfaatan Teknologi Sistem Informasi untuk Meningkatkan Penjualan Hasil Produk UMKM Logam di Kota Pasuruan.” Engagement : Jurnal Pengabdian Kepada Masyarakat 1, no. 2 SE-Articles (30 November 2017). https://doi.org/10.29062/engagement.v1i2.14.

Raya, Moch Khafidz Fuad. "Marketing Jasa Di Institusi Pendidikan (Analisis Pemasaran dalam Pendidikan).” FALASIFA: Jurnal Studi Keislaman 7, no. 1 (2016): 21-52.

Simpson, Mike, Jo Padmore, Nick Taylor, dan Jane Frecknall-Hughes. "Marketing in Small and Medium Sized Enterprises." International Journal of Entrepreneurial Behavior \& Research 12, no. 6 (2006): 361-387.

Taiminen, Heini Maarit, dan Heikki Karjaluoto. "The Usage of Digital Marketing Channels in SMEs.” Journal of Small Business and Enterprise Development 22, no. 4 (2015): 633-651.

Todor, Raluca Dania. "Blending Traditional and Digital Marketing." Bulletin of the Transilvania University of Brasov. Economic Sciences. Series V 9, no. 1 (2016): 51. 